\title{
Methods of Teaching Social Studies: Time Requirements
}

\author{
Smirnov Alexander Vasiljevich \\ Department of General Subjects, Bugulma Construction Technical College, Bugulma, Russia
}

Email address:

savalesmit@mail.ru

\section{To cite this article:}

Smirnov Alexander Vasiljevich. Methods of Teaching Social Studies: Time Requirements. Journal of Political Science and International Relations. Vol. 1, No. 2, 2018, pp. 39-41. doi: 10.11648/j.jpsir.20180102.12

Received: November 28, 2017; Accepted: December 9, 2017; Published: January 30, 2018

\begin{abstract}
Dynamic quantitative and qualitative changes in the socio-political and socio-economic aspects of society, demand the forms and methods of teaching social Sciences in vocational schools. In post-industrial society, with the development of information technology, is required to change approaches to the methods and means of teaching of humanitarian and socio-economic disciplines in College. Shows the qualitative identity of imperfection paradigm component in the training of students. It is proposed to improve the didactic approaches to the teaching of humanitarian and socioeconomic disciplines in the College, enhancing the use of mediainformatsii and learning its interpretation.
\end{abstract}

Keywords: Mathematics, Methods, Teaching, Media Sources of Information

\section{Introduction}

The current stage of development of world civilization is characterized by the transition to the information society. The various flows and a variety of information from all media sources, is inconsistency and the imposition of required perception. It is noted in this controversy: the amount of knowledge increases and motivation to their active use is reduced [1]. It is important to learn to navigate the flow of information, to choose the correct, necessary information to be able to analyze information, be able to own forms, means and methods of obtaining, analyzing, and interpreting information.

\section{Method}

Qualitative and quantitative changes in the spiritual, political, social and economic aspects of society with a growing pace, and sometimes its unpredictability, ambiguity, requires social studies teacher, as they say, "keep abreast". The world is changing, qualitatively and contradictory. We observe the effect of socio-political and socio-economic "weights", the bowls are constantly balancing. The dynamics of these changes encourages students ' manifestation of a negative attitude, which can result in slowing the formation of civic position of a young man. The study of each specific topic of the discipline "social science" is not possible without providing examples from official sources of the media space.
Individual activity learners for assessment of media public-political and socio-economic information can be performed as well as work with the training text, i.e. the theoretical principles, concepts, signs, facts, examples, classification, definition, evaluation, and conclusions. Forms of work with media information can be varied, but it is advisable to build them on the basis of hermeneutics [2], [3], [4]. Insights are viewed as creative tasks to students based on the text. Students demonstrate emotional and personal range of character traits, strengthening the cognitive nature of learning activities [5]. It is important to instil in students, when working with media information, critical thinking [6]. Studies devoted to the hermeneutic analysis of media texts, can be carried out on different materials [7].

\subsection{The Hermeneutic Approach in Media Education}

Hermeneutics in education - the art of interpretation of texts, and today media and information when initially mastering the General competences. Sources of information are characters, words, symbols that come from television channels, radio programs, Internet channels, electronic media publications, official websites of government, social networking, etc Technical equipment and technological capacities of information are expanding and growing every year. Thus, hermeneutics is of particular relevance and new development in the age of post-industrial world economy, 
when the types, sources and streams of information come to the fore. Media as source of information, is a leader in getting information. Significant influence the current media culture, as well as spontaneously, suddenly and widely spreading submetacentric, especially in children's and youth environments. The hermeneutic approach in media education is such a pedagogical system that is based on information flows transmitted via different channels of communication, promotes the development of critical thinking and developing your own worldview.

\subsection{The Importance of Using Media Information}

In 1956 the polymath of the 20th century Alexander A. lyubischev, in his work "On the situation in high school," cited the facts that showed a low level of secondary school graduates. We present only General facts:

1) inability to Express thoughts;

2) weaker interest in the subjects studied;

3 ) the pursuit of the appearance of the works;

4) discipline and moral qualities;

5) a summary of the observations.

As everyone is familiar, close. We are "contemporaries" of the national education system, which was found to be low. Then followed the reformation. Over the past two decades, the Russian education system actually has the same performance on shared values, the Soviet education half a century ago. Education does not develop efficiently and steadily, and, as noted by one of the followers of Marxist philosophy to Vladimir Ilyich Ulyanov (Lenin): "one Step forward, two steps back... It happens in the lives of individuals and in the history of Nations...". Again reform. The abundance of articles, a monograph in favor of how to teach. Teacher providing freedom of creativity, but... in the framework of the Federal state educational standard. Standard pedagogical creativity? Is it conceivable such a thing. The standard system is necessary, but how the Creator will be free in their creativity. No General methodology, General didactic provisions. At the very least, such provisions should appear.

A. A. lyubischev, in the conclusion of its work, "high school" proposed fix "bad" situations in the education system: stand for the high school, separately for the training of specialists, i.e. teachers. Alexander A. lyubischev could afford and such, he was not a bystander, because for five years he worked at the Ulyanovsk pedagogical Institute. "...to increase the authority of teachers..." - one of the proposals of A. A. Lubishchev. Achieved. Was. And what is the authority of teachers in the 21 st century, he who is teacher of postindustrial society? The teacher is a specialist in pedagogical activity, which is the design and implementation of the educational process in educational institutions (of professional standard "the Teacher"). Pedagogical work is a work consisting in the design work.

Explanation only one thing: the country is emerging from the devastating effects of the great Patriotic war. Today, two decades the education system as an assessment of competence at each grade level conducts a final certification in the form of testing (OGE, exam, sample exams, bachelor exams, etc.). Very difficult, very prolonged in time, is a departure from the knowledge paradigm of education to a competence paradigm of education. Psycho-pedagogical conditions of formation of competence of the individual assume a manifestation of acquired knowledge and skills, but a manifestation of the latter is carried out in the solution of typical situations. In the study of social Sciences such a condition is competence in evaluating the dynamic processes of society's spheres (spiritual, social, economic, political).

Qualitative and quantitative changes in the spiritual, political, social and economic aspects of society with a growing pace, and sometimes its unpredictability, ambiguity, requires social studies teacher, as they say, "keep abreast". The world is changing, qualitatively and contradictory. We observe the effect of socio-political and socio-economic "weights", the bowls are constantly balancing. The dynamics of these changes encourages students ' manifestation of a negative attitude, which can result in slowing the formation of civic position of a young man. The study of each specific topic of the discipline "social science" is not possible without providing examples from official sources of the media space.

\subsection{The Media Is a Source of Knowledge}

Widespread use of a variety of electronic educational resources should contribute to the increasing interest in "social Studies", as well as information culture of students. The practice of introducing the relevant information in the classroom, "social Studies" may be in the form of political information. For example, set a sequential order for students on the coverage of relevant socio-political and socioeconomic information. The media space is becoming a source of knowledge. The learner has the opportunity to do the analysis, formulate conclusions. For example, if mastery of individual design and research activity students can be tasked independently to keep a diary of important socio-political and socio-economic developments, self-evaluation of the events.

Applying the hermeneutic approach in teaching of social studies is implemented in the development of the understanding and interpretation of media information. You can talk about the fact that in the 21 st century a hermeneutic personality type, which is characterized by interest in the information. It is important to teach the student to display judgement [8]. Judgments are displayed on the basis of the analysis of any media information. The significant role of media education is given to the media, as they occupy a leading position in the mass communication [9].

\subsection{Knowledge Integration in Learning}

Pedagogical hermeneutics is designed to teach students to navigate in the information fields $[10,11]$. This view corresponds to the theory of "critical thinking development". Any media is authorship, i.e. "forcing" the judgments expressed by one subject or group of subjects. Any received and perceived by the individual information is thought process that subjected them to analysis, synthesis, 
comparison, abstraction and concretization. Understanding leads to the emergence of new subjective semantic content of perceived information [12]. Students integrate their knowledge with new information obtained from a source of media information.

The use of gaming technology such as the game "Gulliver", will contribute to the group project and research activities of students. Monitoring and analysis of economic information from media sources to increase financial literacy of students, interest in tracking this information.

\section{Result}

When you work with media information is used psychopedagogical program [13]. Pedagogical conditions of the program: the ability of students to account for the use of personal time, the analysis of the efficiency of personal time, optimization and increase of efficiency of use of personal time and skills to use in the educational activities of the media in the performance of independent work. Psychological conditions: cognitive motivation of students for effective utilization of personal time, educational motivation of students for self-study media information, persistence in achieving efficient use of personal time, persistence in study of the media information.

\section{Discussion}

Thus, the modern teaching of social studies involves "withdrawal" from the traditional forms and methods of teaching to such methods and forms which will facilitate a more active and meaningful mastery of the competencies in the discipline of "social Studies." Organization of learning activities using media and information sources contributes to the formation of students ' General competences such as to search information necessary for the effective performance of professional tasks (OK-4), to use information and communication technologies in professional activities (OK5). In General, the use of media sources in the classroom of social studies contributes to the development of citizenship among students and the development of media and information literacy, which is understood as a set of "attitudes, knowledge, and skills that allow the individual to determine when and what information is required where and how to obtain it; as it should be to critically evaluate, organize and use in accordance with the ethical rules" [14].

\section{Conclusion}

For the teacher of "social studies" courses are relevant issues-use gaming technology, forms of organization of work of students with various information. In the framework of training, self-education should pay attention to such topics as methods of use of electronic resources in the classroom "social science", the integration of the discipline "social science" and the subjects "History", "Geography".

\section{References}

[1] Anzina T. G., Rozhin E. J., Selivanova, I. V. questions about the media content and the development of critical thinking //New in linguistics and methodology of teaching foreign languages and Russian: Sat. scientific. Tr. on Mat-Lam-I mezhdunar. scientific.-pract. Conf. - Orenburg: IP Pleskonic Tatiana Nikolaevna, 2017.-115 S.-C. 4-12.

[2] Gougnina O. V. Hermeneutics in the teaching of social studies //history of teaching reading.- 004.-No. 8.-P. 289-292.

[3] Samoilov L. P. Hermeneutics and education: from dialogue to method //Izv.]. GOV't. tech. Univ.-2005.-No. 6.-P. 92-96.

[4] Gulevskaya N. A. Gulevsky A. N. The possibility of using the method of hermeneutics in the teaching of the Humanities in the context of the competence approach //Izv. VSTU. A series of "New educational systems and learning technologies at the University." Vol. 10: mezhvuz. SB. nauch. article / VSTU. Volgograd, 2013.-№ 13 (116).-S. 36-38.

[5] Ostrizhnyaya S. G. the formation of the creative qualities of the intelligence of high school students in the process of integration of traditional and innovative approaches in teaching social science /Psychology and pedagogy: methods and problems of practical application.-2010.-No. 13.-P. 161166.

[6] Gougnina O. V. is Active and interactive methods in teaching social studies: textbook.-method. allowance. - Orenburg: Publishing house of the OGPU, 2014.-64 p.

[7] Chelysheva I. V. the Development of critical thinking and media competence of students in the process of analysis of audiovisual media texts: Textbook. allowance. - Taganrog: NP "Center of personality development", 2008.-300 c.

[8] Gadamer H.-G. Truth and method: fundamentals of philosophical hermeneutics: Per. with it.-M.: Progress, 1988.$704 \mathrm{p}$.

[9] Arkhipov B. V., Legotina N.. The formulation of the problem of media education as a means of developing independent thinking students in teaching social Sciences//history of teaching reading.-2004.-No. 8.-P. 239-242.

[10] Belyaeva L. A. the Development of pedagogical hermeneutics as the theory and practice understanding of pedagogy //Pedagogical education in Russia. - 2008. - No. 3.-P. 4-11.

[11] Chelysheva I. V., Mikhaleva G. V. the Basic theoretical concepts of media education in Russia and Britain: a comparative analysis //media education.-2013.-No. 4.-P. 2838.

[12] Zakirova A. F. Fundamentals of pedagogical hermeneutics: Author. a course of lectures. - Tyumen: Publishing house of TSU, 2011.-324 p.

[13] Smirnov A. V. self-organization of the Training as factor of development of cognitive motivation of technical University students: dissertation... the candidate of psychological Sciences.- Samara, 2011.-175 p.

[14] Belyaeva L. A. the Development of pedagogical hermeneutics as the theory and practice understanding of pedagogy //Pedagogical education in Russia. - 2008. - No. 3.-P. 4-11. 